ambulance service trust involved. By law the trust was liable for employees involved in accidents while on duty, but nevertheless the recourse to obtain compensation was through the courts with significant delays.

As a result of our experiences we have undertaken a comprehensive review of our neonatal transport operations. Initial problems of incubator security have been temporarily addressed with ring bolts set into the floor of ambulances which allow secure anchorage with cargo straps. Incubators are loaded using portable ramps. In the long term, in cooperation with our ambulance service, we have redesigned our transport system with a reduced payload around a no lift platform that will be compatible with all types of stretcher. The ambulance service has also undertaken to modify ambulance anchorages to accommodate newer stretcher types with transport incubators on board.

The standards of safety for neonatal transport incubators need to be reviewed. Attention needs to be given to reducing payload, and to the design of systems for loading and securing incubators within ambulances, whether road vehicle or aircraft. The problems of different incubators, ambulances, and stretcher designs can be avoided by using a universal mating platform. Each unit needs to be aware of its responsibilities to its staff regarding liability in the event of an accident.

$$
\begin{array}{r}
\text { R J MADAR } \\
\text { Department of Paediatric Cardiology, } \\
\text { Freeman Hospital, } \\
\text { Newcastle upon Tyne NE7 7DN } \\
\text { D W A MILIIGAN } \\
\text { Newcastle Neonatal Service, } \\
\text { Royal Victoria Infirmary, } \\
\text { Newcastle upon Tyne NE1 } 4 L P
\end{array}
$$

1 Health and Safety Executive. Manual handling, guidance on regulations L23. London: HMSO, 1992.

\section{Unfriendly incubators}

EDITOR,-Fractures in infants of very low birth weight $(\leqslant 1500 \mathrm{~g})$ not related to birth trauma are being recognised with increasing frequency. ${ }^{12}$ These fractures are usually associated with bone demineralisation, which is frequently present in very low birthweight infants, ${ }^{3}$ and almost two thirds of them involve the extremities. ${ }^{1}$ Fractures in these infants can occur as the result of 'trauma' during physiotherapy or other procedures such as placement of intravenous lines. ${ }^{145}$

We have observed four infants with birth weights under $1000 \mathrm{~g}$ who sustained traumatic fractures of the extremities (one arm in three cases, one leg in the other), and we believe that the contributing factor was accidental trapping of the extremity by or under the plastic tray on which the mattress of the incubator lies. The fractures, diagnosed radiologically between 4 and 6 weeks of age, were associated with overlying bruising. Two of these babies also had well documented bone demineralisation. Subsequent to these independent observations in Athens and Montreal, we conducted a survey of incubators used in neonatal intensive care units and found that in many (even in some of the latest models) there was sufficient gap between the plastic tray and the incubator wall for an arm or a leg of the baby to slip between the incubator's wall and the plastic tray (figure). In many instances the nursing staff had tried to cover this gap with rolled sheets. In some incubators the tilting mechanism could not be securely locked at the desired tilted position

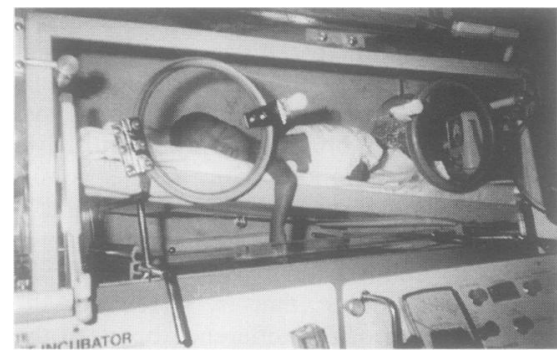

Incubator showing gap between plastic tray and wall allowing arm to be trapped.

and the plastic tray could therefore accidentally fall or jolt on the trapped arm or leg. Injury might also occur if the baby is pulled or turned by a nurse or a doctor unaware that a limb is trapped. The possibility that a fracture may be caused in this manner is enhanced if the bones are significantly demineralised.

The design of an incubator should be such that the plastic tray extends to the wall of the incubator such that any gap is too small for a baby's extremity to slip through and the tilting mechanism should be securely locked at the desired tilt. Incubators currently in use should be checked for this potential hazard.

H D DELLAGRAMMATICAS Neonatal Intensive Care Unit,
2nd Department of Pediatrics, University of Athens,
Aglaia Kyriakou Children's Hospital,
Athens, Greece Athens, Greece

A PAPAGEORGIOU Department of Neonatology, The SMBD-fewish General Hospital, 3755 Cote St Catherine Road, Room B-511, Montreal, Quebec H3T 1E2,

Canada

1 Koo WW, Sherman R, Succop P, et al. Fractures and rickets in very low birthweight infants: conservative management and outcome. $\mathcal{F}$ Pediat Orthop 1989; 9: 326-30.

2 Amir J, Katz K, Grunebaum M, Yosipovich Z Wielunsky E, Reisner SH. Fractures in premature infants. 7 Pediatr Orthop 1988; 8, premat

3 James JR, Congdon PJ, Truscott J, Horsman A, Arthur R. Osteopenia of prematurity. Arch Dis Child 1986; 61: 871-6.

4 Helfer RE, Scheurer SL, Alexander R, Reed J Slovis TL. Trauma to the bones of small infants flovis TL. Trauma to the bones of small infants from passive exercise: a factor in the etio
child abuse. $\mathcal{f}$ Pediatr 1984; 104: 47-50.

5 Phillips RR, Lee SH. Fractures of long bones occurring in neonatal intensive therapy units. $B M \mathcal{F}$ 1990; 301: 225-6.

Excessive rates of asphyxia - acecdote or fact?

EDITOR,-It is well known that hypoxic ischaemic encephalopathy (HIE) in neonates is associated with adverse neurological outcomes. ${ }^{1} 2$ The incidence of HIE can be a useful indicator of quality of intrapartum care provided to term infants, ${ }^{3}$ while the severity relates to subsequent neurological outcome. ${ }^{2}$ The Doncaster perinatal service has received much adverse publicity suggesting that their incidence of HIE was excessive ('Trial of labour', World in Action, Granada Television, 2 Nov 1992). We analysed data from the Trent Regional Neonatal Survey in order to establish if these criticisms were valid.

The Trent Regional Neonatal Survey collects data on all high risk babies admitted to perinatal units within the region. All babies greater than 35 weeks' gestation admitted because of HIE were included in this analysis. HIE was diagnosed using modified criteria of

\begin{tabular}{|c|c|c|c|c|c|}
\hline \multirow{2}{*}{$\begin{array}{l}\text { Unit } \\
\text { (deliveries } \\
\text { /year) }\end{array}$} & \multicolumn{3}{|c|}{$\begin{array}{l}\text { No of babies with } \\
\text { IHE }\end{array}$} & \multirow{2}{*}{$\begin{array}{l}\text { Rate of } \\
\text { HIE/ } \\
1000 \\
\text { live } \\
\text { births }\end{array}$} & \multirow{2}{*}{$\begin{array}{l}95 \% \\
\text { Confidence } \\
\text { interval }\end{array}$} \\
\hline & $\begin{array}{l}\text { Grade } \\
\text { II }\end{array}$ & $\begin{array}{l}\text { Grade } \\
\text { III }\end{array}$ & Total & & \\
\hline \multicolumn{6}{|l|}{$<3000$} \\
\hline 1 & 1 & 4 & 5 & 0.58 & 0.24 to 1.42 \\
\hline 2 & 4 & 0 & 4 & 0.98 & 0.13 to $7 \cdot 24$ \\
\hline 3 & 7 & 8 & 15 & $1 \cdot 8$ & 1.07 to 3.02 \\
\hline 4 & 14 & 5 & 19 & $5 \cdot 1$ & 3.22 to 8.07 \\
\hline & 14 & 4 & 18 & $3 .($ & 1.87 to 4.81 \\
\hline \multicolumn{6}{|c|}{$3001-4500$} \\
\hline 6 & 10 & 9 & 19 & 1.9 & 1.20 to 3.01 \\
\hline 7 & 1 & 7 & 8 & $0 \cdot 76$ & 0.37 to 1.54 \\
\hline 8 & 4 & 11 & 15 & 1.49 & 0.89 to 2.50 \\
\hline 9 & 7 & 3 & 10 & 1.08 & 0.57 to 2.03 \\
\hline 10 & 11 & 7 & 18 & 1.71 & 1.07 to 2.74 \\
\hline $\begin{array}{c}11 \\
>4500\end{array}$ & 8 & 14 & 22 & 1.85 & 1.21 to 2.83 \\
\hline \multicolumn{6}{|l|}{$>4500$} \\
\hline $\begin{array}{l}12 \\
13\end{array}$ & 13 & 8 & 21 & 1.53 & 0.99 to 2.37 \\
\hline 13 & 16 & 8 & 24 & 1.53 & 1.02 to $2 \cdot 30$ \\
\hline 14 & 12 & 8 & 20 & $1 \cdot 16$ & 0.74 to 1.81 \\
\hline 15 & 7 & 9 & 16 & $1 \cdot 1$ & 0.67 to 1.81 \\
\hline 16 & 12 & 17 & 29 & 1.73 & $1 \cdot 20$ to $2 \cdot 40$ \\
\hline \multicolumn{6}{|l|}{ Total live } \\
\hline $\begin{array}{l}\text { births } \\
(16843\end{array}$ & 141 & 122 & 263 & 1.56 & 1.38 to 1.76 \\
\hline
\end{tabular}
Levene $e t$ al. ${ }^{2}$ Grade II HIE was defined as the infant having a history suggestive of asphyxia plus convulsions, while grade III was defined
The incidence of HIE in Trent perinatal units between 1990-3

as grade II plus the need for respiratory support. Data was collected by two independent visiting observers. The last three years of complete data were analysed (1 April 1990-30 March 1993).

There were a total of 168435 live births in 16 perinatal centres (five subregional units and 11 smaller units) and 263 babies with HIE; 141 grade II and 122 grade III (table). The incidence of HIE for the region was 1.56 per 1000 live births (range $0 \cdot 58-5 \cdot 1$ per 1000 live births). The Doncaster unit (number 6 in the table) had an incidence of 1.53 per 1000 live births - that is, similar to the region as a whole.

It is clear that criticisms levelled at this perinatal unit were unfounded and based on anecdotal evidence rather than fact. Data relating to HIE is not routinely collected by most perinatal units, however, we believe such data provide a valuable method of evaluating perinatal care. Only if the rate of HIE falls outside the 'normal range' is concern warranted.

$S$ BOHIN

E S MASON D J FIELD

Department of Child Health Leicester Royal Infirmary, $P O B$ Box 65 Leicester LE2 7LX

1 Levene MI, Kornberg J, Williams THC. The incidence and severity of post asphyxial encephalopathy in full-term infants. Early Hum Dev 1985; 11: 21-6.

2 Levene MI, Sands C, Grindulis H, Moore JR. Comparison of two methods of predicting outcome in perinatal asphyxia. Lancet 1986; i 67-8.

3 Dennis J, Chalmers I. Very early neonatal seizure rate: a possible epidemiological indicator of the 1982; 89: 418-26.

\section{Diagnosis and management of}

non-immune hydrops in the newborn

EDITOR,-We read with interest the article by Stephenson et al on the diagnosis of nonimmune hydrops in the newborn, ${ }^{1}$ and we would like to emphasise that a wide range of inborn errors of metabolism (IMD) have been reported to be associated with non-immune hydrops and in many cases a feasible pathogenetic mechanism can be hypothesised. ${ }^{2}$ As a cause of hydrops they are rare 
but collectively they are significant and hence appropriate investigations should be considered. It is particularly important to consider IMD where more than one case of hydrops occurs in the same family or if there is a history of spontaneous abortion or unexplained deaths in close family members. We would like to describe our protocol for the investigation of fetal and neonatal hydrops for IMD. These investigations are considered when the more common causes of hydrops have been excluded.

From the dead fetus a skin biopsy can be taken for culture. This should be taken as soon as possible. The cultured cells can be assayed for $\beta$-galactosidase (GM1 gangliosidosis, Morquio's disease type B, galactosialidosis), $\beta$-glucuronidase (Sly's disease), $\beta$-glucosidase (Gaucher's disease), $\alpha$-neuraminidase (mucolipidosis I), $N$-acetylgalactosamine-6-sulphate sulphatase (Morquio's disease type A), sialic acid (sialic aciduria) and cholesterol esterification (Niemann-Pick C). DNA from the cultured cells can be investigated for the expanded trinucleotide repeat sequence found in myotonic dystrophy.

In cases where hydrops has been diagnosed antenatally amniotic fluid can be tested for I-cell disease and some mucopolysaccharide disorders. Other assays can be undertaken on cultured amniotic fluid cells or chorionic villus tissue (direct or cultured). In the live neonate investigations which can be performed on blood include pyruvate kinase, plasma lysosomal enzymes, plasma carnitine, iron, and ferritin (neonatal haemochromatosis). A skin biopsy may be preferable if a large number of lysosomal enzyme assays are to be assayed. A random urine specimen $(10 \mathrm{ml})$ can be investigated by mucopolysaccharide electrophoresis and oligosaccharide chromatography. Liver tissue may be of value for liver iron quantitation and possibly also for enzyme assays. If liver is to be taken, it should be frozen immediately and stored below $-20^{\circ} \mathrm{C}$.

While not all these tests will be indicated on every case of hydrops it is important to consider inborn errors of metabolism as a cause of non-immune hydrops and to collect appropriate specimens for investigations where indicated. Hence discussion with a specialist centre for inherited metabolic disorders is important.

$$
\begin{array}{r}
\text { R G F GRAY } \\
\text { A GREEN } \\
\text { West Midlands Regional Laboratory for Inherited } \\
\text { Metabolic Disorders, } \\
\text { Department of Clinical Chemistry, } \\
\text { The Children's Hospital, } \\
\text { Birmingham B16 8ET }
\end{array}
$$

1 Stephenson T, Zuccollo J, Mohajer M. Diagnosis and management of non-immune hydrops in 2 Gillan JE, Lowden JA, Gaskin K, Cutz E. Congenital ascites as a presenting sign of lysoCongenital ascites as a presenting sign of lyso-
somal storage disease. $\mathcal{F}$ Pediatr 1984; 104: 225-31.

\section{Do maternal $\beta$-sympathomimetics influence the development of} retinopathy in the premature infant?

EDITOR,-Recent studies suggest that a number of factors other than the injudicious delivery of oxygen contribute to the development of retinopathy in the premature infant. ${ }^{12}$ One hundred and fifty infants on our neonatal unit who required oxygen treatment for more than 60 days were reviewed retrospectively in order to determine the range of factors contributing to this pathol- ogy. All infants requiring oxygen for more than two weeks were examined at two weekly intervals by an ophthalmic surgeon (ES). Fourteen cases of retinopathy greater than stage 3 were identified. These patients were matched for gestation ( \pm 1 week), birth weight $( \pm 50 \mathrm{~g})$, sex, and ethnic group with infants who had oxygen requirements for more than 60 days, but did not have retinopathy. The two sets of cases showed no significant differences in their Apgar scores, requirement for exchange transfusions, or the incidence of clinically significant patent ductus arteriosus.

Mothers of eight of the retinopathy group had received infusions of $\beta$-sympathomimetics (seven ritodrine, one salbutamol) to arrest premature labour: only one of the nonretinopathy group had received ritodrine $(p<0.008)$. This observation may be of physiological importance, as animal experiments have suggested that the retinal circulation is strongly influenced by these pharmacological agents acting jointly through the sympathetic nervous system and endothelial factors. ${ }^{3} \beta$-Sympathomimetics are known to induce transient ischaemic changes in the myocardium of the newborn if given over long periods by inducing vasospasm. ${ }^{4}$ Maternal ritodrine has been associated with reduced blood pressure in the newborn. ${ }^{56}$ In the premature infant in whom antenatal retinal perfusion is influenced by $\beta$-sympathomimetics, there may therefore be a predisposition to damage by other factors, including inappropriate oxygen tensions. This combination of insults to retinal perfusion could lead to the development of ischaemia, and predispose to retinopathy of prematurity. This observation merits review in a larger series of infants. Further, it casts doubt as to the safety of $\beta$-sympathomimetics which are widely used in the therapy of premature labour with little evidence to support their efficacy.

$$
\begin{array}{r}
\text { C A MICHIE } \\
\text { S BRAITHWAITE } \\
\text { E SCHULENBERG } \\
\text { D HARVEY } \\
\text { Department of Paediatrics and Neonatal Medicine, } \\
\text { Royal Postgraduate Medical School, } \\
\text { Hammersmith Hospital, } \\
\text { London W12 ONN }
\end{array}
$$

1 Cooke RWI, Clark D, Hickey-Dwyer $M$ Weindling AM. The apparent role of blood transfusions in the development of retrolenta fibroplasia. Eur $\mathcal{F}$ Pediatr 1993; 152: 833-6.

2 Lucey JF, Dangman B. A reexamination of the role of oxygen in retrolental fibroplasia. Pediatrics 1984; 73: 82-96.

3 Prendeville A, Schulenberg WE. Clinical factors associated with retinopathy of prematurity. Arch Dis Child 1988; 63: 522-7.

4 Miyamura N, Uji Y. Effects of carteolol on electroretinograms in isolated perfused cat eye. Nippon Ganka Gakkai Zasshi 1992; 96: 878-83.

5 Gemelli M, De-Luca F, Manganaro R, et al. Transient electrocardiographic changes suggesting myocardial ischaemia in newborn infants ing myocardial ischaemia in newborn infants following tocolysis with beta sym

6 Aarimaa T, Ekblad U, Erkkola R, Kanto J, Kero $P$. Effect of antepartum ritodrine on the cardiorespiratory status of the newborn after elective caesarean section. Gynecol Obstet Invest 1987; 23: 160-6.

Immunisation and $\mathbf{C}$ reactive protein in infants on neonatal intensive care units

EDITOR,-C reactive protein estimation is a well known indirect method of detecting bacterial infection in neonates. ${ }^{1}$ Premature infants on our neonatal unit receive their primary course of immunisation for diphtheria, pertussis, tetanus and Haemophilus influenzae $b$ as per the immunisation schedule at two, three, and four months postnatally. ${ }^{2}$

Plasma $\mathrm{C}$ reactive protein estimation is performed as part of a weekly or daily infection surveillance. Serial estimations are continued in infants with an increased concentration (normal $<4 \mathrm{mg} / \mathrm{l}$ ). We noticed, as an incidental finding, that values increased within 24 hours of immunisation.

During a period of three months (November 1993 to January 1994) 12 babies had $\mathrm{C}$ reactive protein estimations before and after immunisation. The median value preimmunisation was $<4 \mathrm{mg} / \mathrm{l}$ (range $<4-7 \cdot 1)$. Postimmunisation the concentrations increased in all of the 12 babies. The median value at 24 hours postimmunisation was $10 \cdot 3 \mathrm{mg} / 1$ (range $8 \cdot 0-47 \cdot 1$ ), and at 48 hours the median value was $18 \mathrm{mg} / \mathrm{l}$ (range $4 \cdot 2-48 \cdot 6$ ). The median duration of increased $C$ reactive protein was two days. During the initial period of the study one of the babies had a full infection screen based on the raised $C$ reactive protein and clinical findings (systemically unwell, postimmunisation).

Plasma C reactive protein is known to increase after immunisation with diphtheria, pertussis, and tetanus vaccines in malnourished children after nutritional recovery. ${ }^{3}$ To the best of our knowledge it has not been reported in premature infants who have been immunised. It is important to realise that immunisation leads to an increase in the plasma $C$ reactive protein concentrations so that unnecessary investigations may be avoided.

$$
\begin{array}{r}
\text { D R BALKUNDI } \\
\text { J A NYCYK } \\
\text { R W I COOKE } \\
\text { Regional Neonatal Intensive Care Unit, } \\
\text { Department of Child Health, } \\
\text { Liverpool Maternity Hospital, } \\
\text { Oxford Street, } \\
\text { Liverpool L7 } 7 B N
\end{array}
$$

1 Russell GAB, Smyth A, Cooke RWI. Receiver operating characteristic curves for comparison of serial neutrophil band forms and $C$ reactive protein in neonates at risk of infection. Arch Dis Child 1992; 67: 808-12.

2 Immunisation against infectious disease. London: HMSO, 1992.

3 Doherty JF, Golden MH, Raynes JG, Griffin GE, McAdam KP. Acute phase protein response is impaired in severely malnourished children. Clin Sci 1993; 84: 169-75.

\section{Diagnosis and management of} non-immune hydrops in the newborn

EDITOR,-The article by Stephenson and colleagues concerning the diagnosis and management of non-immune fetal hydrops was both informative and concise; the table of reported associations was particularly thorough. ${ }^{1}$ I would like to make a minor point regarding the inclusion of asplenia syndrome among the cardiovascular associations.

Asplenia syndrome (right atrial isomerism) is characterised by complex cardiac defects including primitive atrioventricular septal defects and pulmonary atresia, ${ }^{2}$ both of which are listed in Stephenson's table $1 .^{1}$ Nevertheless, it is far more common to see polysplenia syndrome (left atrial isomerism) in association with fetal hydrops. ${ }^{3}{ }^{4}$ Left atrial isomerism is well associated with complete atrioventricular block, as well as other structural cardiac lesions. ${ }^{3}$ Complete heart block can occur, rarely, in right atrial isomerism, as in one case in Schmidt's study 